\title{
Mortalidade no trânsito do Maranhão após a implantação da lei seca
}

\author{
Mortality in the transit of Maranhão after the implementation of the dry law \\ Mortalidad en el tránsito de Maranhão tras la aplicación de la ley seca
}

Lucas Henrique Ferreira de Sousa ${ }^{1}$, Sueli de Souza Costa ${ }^{1}$, Izolda Souza Costa ${ }^{2 *}$, Daizy Carlota Coelho Aguiar ${ }^{1}$, Jessica Ferreira Bertoldo ${ }^{1}$, Ítalo Henrique Pereira Lima ${ }^{1}$, Taynah Calixto Martins ${ }^{1}$, Daniel Santos Uchoa ${ }^{1}$, José Carlos Aragão Silva Júnior ${ }^{1}$, Túlio Gabriel de Lima Cavalcanti Tôrres'.

\section{RESUMO}

Objetivo: Analisar a mortalidade no trânsito do estado Maranhão e os impactos da implementação da Lei no 11.705/2008, popularmente conhecida como "Lei Seca". Métodos: Dados de atestados de óbitos de 2005 a 2017 foram obtidos em plataforma digital do DATASUS do Ministério da Saúde e trabalhados no programa Microsoft Excel, sendo os óbitos divididos em grupos. Resultados: A mortalidade no trânsito representou cerca de 4,50\% das mortes do período. Grande parte desta porcentagem foi de adultos jovens, porém, quando comparada por 100 mil habitantes, os idosos perfazem a maioria. O sexo masculino apresentou a maior mortalidade, cerca de $82,90 \%$ dos óbitos por acidente de trânsito. O grupo "motociclistas" demostrou o maior aumento da mortalidade no período do estudo. Conclusão: Percebeu-se queda da mortalidade no ano posterior à implementação da Lei no 11.705/2008 e nos anos em que houve alterações na mesma. Melhorar a fiscalização e aumentar ações de conscientização sobre a Lei Seca pode resultar em quedas na taxa de mortalidade por acidente de trânsito.

Palavras-Chave: Acidentes de trânsito, Atestado de óbito, Mortalidade, Condução de veículo.

\section{ABSTRACT}

Objective: To analyze traffic mortality in the state of Maranhão and the impacts of implementing Law No. 11,705 / 2008, popularly known as "Dry Law." Methods: Data from death certificates from 2005 to 2017 were obtained on a platform digital on DATASUS of the Ministry of Health and worked in the Microsoft Excel program, with the deaths being divided into groups. Results: Traffic mortality represented about $4.50 \%$ of the deaths in the period. Much of this percentage was of young adults, however, when compared per 100,000 inhabitants, the elderly make up the majority. The male sex had the highest mortality, about $82.90 \%$ of deaths from traffic accidents. The group "motorcyclists" showed the highest increase in mortality during the study period. Conclusion: A decrease in mortality was noticed in the year after the implementation of Law No. 11,705 / 2008 and in the years when there were changes in it, improving inspection and increasing awareness actions on Prohibition can result in declines in the mortality rate due to traffic accidents.

Keywords: Traffic accidents, Death certificate, Mortality, Driving.

\section{RESUMEN}

Objetivo: Analizar la mortalidad por tránsito en el estado de Maranhão y los impactos de la implementación de la Ley N`11.705 / 2008, conocida popularmente como "Ley Seca". Métodos: Los datos de los certificados de defunción de 2005 a 2017 se obtuvieron en una plataforma digital del DATASUS del Ministerio de Salud y trabajó en el programa Microsoft Excel, dividiendo las muertes en grupos. Resultados: La mortalidad por tránsito representó alrededor del $4.50 \%$ de las muertes en el período. Gran parte de este porcentaje fue de adultos jóvenes, por cada 100.000 habitantes, los ancianos constituyen la mayoría. El sexo masculino tuvo la mayor mortalidad, alrededor del $82,90 \%$ de las muertes por accidentes de tráfico. El grupo "motociclistas" mostró el mayor aumento de mortalidad durante el período de estudio. Conclusión: Se notó una disminución de la mortalidad en el año posterior a la implementación de la Ley $N^{\circ} 11.705 / 2008$ y en los años en que hubo cambios en la misma, mejorando la fiscalización y aumentando las acciones de sensibilización sobre La prohibición puede resultar en una disminución en la tasa de mortalidad debido a accidentes de tráfico.

Palabras clave: Accidentes de tráfico, Certificado de defunción, Mortalidad, Conducción.

${ }^{1}$ Universidade Federal do Maranhão (UFMA), Pinheiro - MA.

${ }^{2}$ Universidade Federal do Maranhão (UFMA), São Luís - MA. *E-mail: izolda.costa@hotmail.com 


\section{INTRODUÇÃO}

Após a Segunda Guerra mundial, os veículos locomotores transformaram-se em fenômeno de massa e, ao longo do tempo, foi se tornando mais presente no cotidiano (MARÍN L e QUEIROZ MAS, 2020). Segundo dados do Departamento Nacional de Trânsito (DENATRAN), em 1998 havia cerca de 24,3 milhões de veículos no Brasil; já em abril de 2018, esse número superou 98,2 milhões (DENATRAN, 2019).

Apesar do aumento na quantidade de veículos ter trazido benefícios, como a maior facilidade para a locomoção, trouxe também problemas, como a poluição ambiental e os acidentes de trânsito (AT). Estes geram gastos que no período de julho de 2004 a julho de 2005 eram estimados pelo Instituto de Pesquisa Econômica Aplicada (IPEA) em R $\$ 22$ bilhões, além de 150 mil pessoas mortas ou feridas passando para cerca de $\mathrm{R} \$ 50$ bilhões, além de 345 mil pessoas mortas ou feridas em 2014 (IPEA, 2006; BACCHIERI G e BARROS AJD, 2011; IPEA, 2015).

O Brasil é considerado um dos países com trânsito mais violento no mundo. Tentando conter essa violência, algumas atitudes foram efetivadas pelo governo federal, como a implantação do novo Código de Trânsito Brasileiro (CTB) em 1998 e a Lei no 11.705 de 19 de junho de 2008, que ficou conhecida como Lei Seca, visando punir mais severamente quem faz ingesta de álcool e conduz um veículo, estabelecendo alcoolemia zero e punições que variam de multas à prisão (BRASIL, 2008).

O álcool, por ser uma droga lícita no Brasil, é consumido amplamente e tem seu consumo influenciado pela indústria, que complica a sua percepção como problema de saúde pública (ARAÚJO TA, et al., 2015). Seus efeitos no organismo variam conforme a quantidade ingerida, oscilando de euforia a psicose (DAMACENA GN, et al., 2016; SADOCK BJ, et al., 2017). Os homens são os que mais fazem ingesta das bebidas alcoólicas, predominando na faixa etária de 40 a 49 anos (DAMACENA GN, et al., 2016).

O consumo de álcool traz alterações no tempo de reação, na atenção, no senso de velocidade, na sonolência e em outros fatores do comportamento e pensamento humanos, com isso podendo precipitar acidentes de trânsito (DAMACENA GN, et al., 2016).

Segundo Sadock BJ, et al. (2017), uma concentração de 0,2g/L é capaz de provocar alterações motoras e reduzir a capacidade de raciocínio do indivíduo. No Brasil, o consumo de álcool é um dos principais fatores causais de acidente, estimando que seja o principal responsável em $70 \%$ dos AT violentos com morte (ABREU AMM, 2010).

A maior parte dos envolvidos em AT são homens jovens, tanto os que fazem a combinação do uso de álcool e direção, quanto os que não ingerem bebida alcoólica e dirigem, mas havendo maior prevalência entre os primeiros (DAMACENA GN, et al., 2016).

Morte no trânsito ocorre com frequência. Muitas dessas mortes estão associadas ao consumo de bebidas alcoólicas, apesar da existência de inúmeras campanhas que são divulgadas diariamente nos meios de comunicação de massa objetivando a prevenção de AT. Cerca de 1,2 milhões de pessoas morrem por ano no mundo vítimas de AT, sendo que, no Brasil, essa ocorrência com pessoas que fizeram uso de bebida alcoólica é quase o dobro em relação as que não consumiram (ARAÚJO TA, et al., 2015; DAMACENA GN, et al., 2016). Muitas dessas mortes são de terceiros, ocasionando um gasto ainda maior para o sistema de saúde, além de deixar várias famílias em sofrimento (BACCHIERI G e BARROS AJD, 2011).

Uma pesquisa realizada em 2005, antes da edição da Lei no 11.705/2008 (Lei Seca), mostrou que, somente no Rio de Janeiro, das 94 vítimas fatais de acidente de trânsito que tinham realizado o exame de alcoolemia, 83 apresentavam álcool no organismo (ABREU AMM, 2010). Objetivando diminuir estes índices, o governo federal implantou a Lei Seca (BRASIL, 2008). Ao longo dos anos, essa lei passou por várias alterações, tornando-se mais punitiva e visando diminuir ainda mais a mortalidade por ingesta de álcool.

Diante deste quadro, o objetivo deste trabalho é analisar a mortalidade no trânsito do estado Maranhão e os impactos da implementação da Lei ํำ11.705/2008. 


\section{MÉTODOS}

Este estudo foi realizado utilizando dados secundários disponíveis em plataforma digital do Departamento de Informática do SUS, do Ministério da Saúde (DATASUS, 2018). Trata-se de um estudo quantitativo de abordagem descritiva em que foram analisadas as informações das Declarações de Óbitos do estado do Maranhão no período 2005-2017. O ano de 2005 foi escolhido para haver uma evolução de alguns anos antes da implantação da Lei Seca, sancionada em 2008. Já o ano de 2017 foi selecionado devido ser o último ano disponível até a data do início do presente estudo.

Foram selecionadas para análise todas as informações das Declarações de Óbitos que tiveram em seu preenchimento do campo "Causa Básica" na Classificação Estatística Internacional de Doenças e Problemas Relacionados à Saúde (CID-10) elencados na sequência abaixo. A CID-10 foi realizada através da Nomenclatura Internacional de Doenças, que foi estabelecida pela Organização Mundial de Saúde (OMS), e tem como objetivo uniformizar e pautar as doenças e problemas relacionados à saúde no Brasil (DATASUS, 2018). Após a seleção dos CID, agrupamos em seis grupos de óbitos de indivíduos no trânsito (pedestres; ciclistas; motociclistas; condutores; passageiros; não especificado), para facilitar a análise, conforme Tabela 1.

Tabela 1 - Grupos de óbitos de indivíduos no trânsito com os respectivos CID.

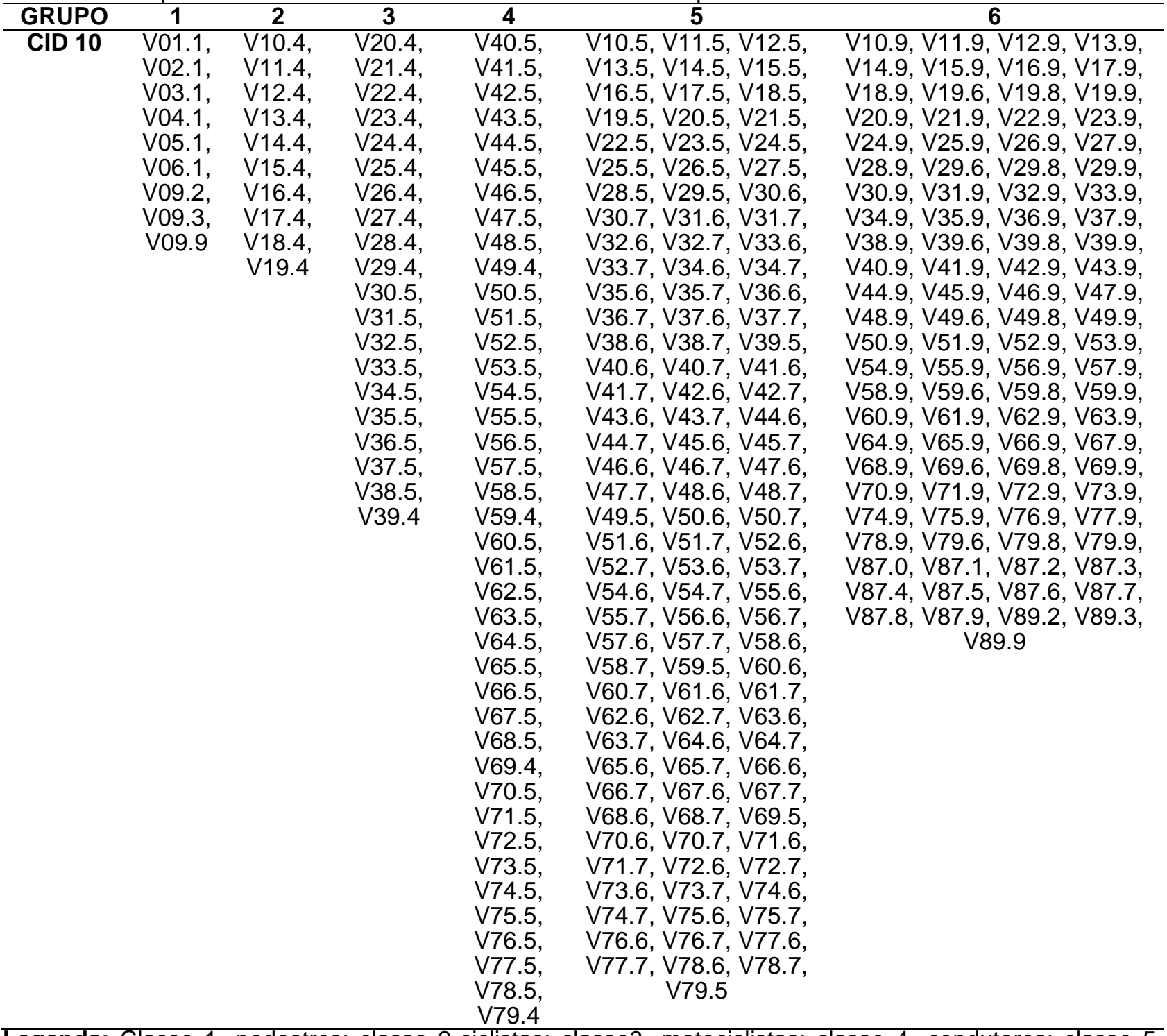

Legenda: Classe 1- pedestres; classe 2-ciclistas; classe3- motociclistas; classe 4- condutores; classe 5passageiros; classe 6- não especificado

Fonte: Dados extraídos do CID-10, disponível em <www.medicinanet.com.br> CID-10. Dados coletados por Sousa LHF, et al, 2020. 
Foram excluídos aqueles CID que continham acidentes envolvendo veículos, mas não caracterizados como acidente de trânsito ou que não especificavam se eram AT ou não. Foram desconsiderados AT de ocupantes de trem, bonde, veículos especiais de áreas industriais, veículos agrícolas, veículos especiais de construção, veículos especiais para qualquer terreno, e outros veículos a motor projetados essencialmente para uso não em via pública.

Além disso, foi realizado levantamento da frota de automóveis no estado do Maranhão nos anos estudados. Este também disponível digitalmente no portal do DENATRAN (2019). Para facilitar a análise, os automóveis foram classificados em dois grupos, denominados frota de carros e frota de motocicletas. $O$ primeiro grupo é composto por: automóvel, caminhão, caminhão trator, caminhonete, camioneta, chassi plataforma, micro-ônibus, ônibus, utilitários. O segundo grupo é composto por: ciclomotor, motocicleta, motoneta, quadriciclo, sidecar, triciclo. Foram considerados apenas aqueles veículos com placa, obrigatoriamente do Maranhão, desconsiderando demais veículos. O cálculo da frota anual foi realizado através da média das frotas mensais.

Para o cálculo da taxa de mortalidade, foi utilizada a projeção populacional do Instituto Brasileiro de Estatística (IBGE) do ano de 2013, visto ser a última projeção que apresenta a população de todos os anos do presente estudo (IBGE, 2018). As informações coletadas foram inseridas no programa Microsoft Excel 2010. As variáveis foram apresentadas em frequências (absoluta e relativa) e taxas de mortalidade por 100 mil habitantes e por 100 mil veículos, sendo este último ainda subdividido nas taxas de mortalidade por 100 mil motocicletas e por 100 mil carros.

\section{RESULTADOS}

No período estudado tiveram 371.758 mortes no estado do Maranhão, das quais 16.717 foram por AT, o que equivale a aproximadamente $4,50 \%$ das mortes nesse período. Esta passou de 858 em 2005 para 1.320 em 2017 , correspondendo a um aumento de $53,85 \%$. Neste mesmo período, a frota de veículos passou de 337.769 para 1.566 .606 , representando um aumento de $363,81 \%$.

A mortalidade por AT por 100 mil habitantes teve alta de 36,67\%, passando de 13,80 para 18,86 óbitos. Destaca-se o ano de $2006 \mathrm{com}$ a menor taxa de mortalidade (12,71), e $2014 \mathrm{com}$ a maior taxa do período $(24,6)$. Quando comparado à mortalidade por 100 mil veículos, observa-se uma queda de $66,83 \%$, passando de 254,02 para 84,26 (Tabela 2).

Tabela 2 - Números globais relativos à mortalidade por acidente de trânsito, frota de veículos e sexo.

\begin{tabular}{|c|c|c|c|c|c|c|c|c|}
\hline \multirow{3}{*}{ Ano } & \multicolumn{2}{|c|}{ Mortalidade } & \multicolumn{2}{|c|}{ Frota } & \multicolumn{4}{|c|}{ Sexo* } \\
\hline & \multirow{2}{*}{$\mathbf{N}$} & \multirow{2}{*}{ Taxa (1) } & \multirow{2}{*}{$\mathbf{N}$} & \multirow{2}{*}{ Taxa (2) } & \multicolumn{2}{|c|}{ Masculino } & \multicolumn{2}{|c|}{ Feminino } \\
\hline & & & & & $\mathbf{N}$ & Taxa (3) & $\mathbf{N}$ & Taxa (4) \\
\hline 2005 & 858 & 13,80 & 337.769 & 254,02 & 672 & 21,64 & 185 & 5,94 \\
\hline 2006 & 801 & 12,71 & 384.738 & 208,19 & 653 & 20,77 & 148 & 4,69 \\
\hline 2007 & 983 & 15,40 & 444.513 & 221,14 & 800 & 25,15 & 183 & 5,72 \\
\hline 2008 & 1.131 & 17,51 & 519.821 & 217,57 & 933 & 29,01 & 197 & 6,08 \\
\hline 2009 & 1.073 & 16,42 & 609.510 & 176,04 & 878 & 27,01 & 195 & 5,94 \\
\hline 2010 & 1.251 & 18,94 & 724.987 & 172,55 & 1.004 & 30,59 & 247 & 7,44 \\
\hline 2011 & 1.388 & 20,81 & 867.578 & 159,99 & 1.172 & 35,38 & 216 & 6,43 \\
\hline 2012 & 1.599 & 23,74 & 1.007 .427 & 158,72 & 1.330 & 39,80 & 269 & 7,93 \\
\hline 2013 & 1.515 & 22,30 & 1.143 .762 & 132,46 & 1.266 & 37,58 & 249 & 7,27 \\
\hline 2014 & 1.685 & 24,60 & 1.274 .305 & 132,23 & 1.416 & 41,73 & 269 & 7,78 \\
\hline 2015 & 1.548 & 22,42 & 1.395 .774 & 110,91 & 1.323 & 38,72 & 224 & 6,42 \\
\hline 2016 & 1.565 & 22,50 & 1.489 .709 & 105,05 & 1.304 & 37,92 & 261 & 7,43 \\
\hline 2017 & 1.320 & 18,86 & 1.566 .606 & 84,26 & 1.107 & 33,54 & 212 & 6,34 \\
\hline Total & 16.717 & 19,35 & 11.766 .499 & 142,07 & 13.858 & 32,30 & 2.855 & 6,56 \\
\hline
\end{tabular}

Legenda: *4 mortes não continham o sexo.

(1) Taxa de mortalidade por 100 mil habitantes (2) Taxa de mortalidade por 100 mil veículos

(3) Taxa de mortalidade por 100 mil Homens (4) Taxa de mortalidade por 100 mil Mulheres

Fonte: Sousa LHF, et al., 2021; dados extraídos do DATASUS (2018), IBGE (2018) e DENATRAN (2019). 
Considerando-se todos os grupos estudados, o denominado "Não Especificado" apresentou maior taxa de mortalidade, correspondendo a $60,51 \%$ das mortes por AT, seguido de motociclistas $(15,22 \%)$ e pedestres $(15,21 \%)$. Houve queda na taxa de mortalidade dos pedestres, enquanto os demais grupos tiveram aumento, sendo os motociclistas o grupo com maior alta $(282,76 \%)$, seguido dos condutores (103,45\%), porém ambos tiveram redução na mortalidade por 100 mil veículos, apresentando uma taxa média de 37,75 e 7,58 respectivamente (Tabela 3 ).

Tabela 3 - Mortalidade total e taxa de mortalidade por 100 mil habitantes, por grupo de óbitos de indivíduos no trânsito.

\begin{tabular}{|c|c|c|c|c|c|c|c|c|c|c|c|c|c|c|}
\hline \multirow{3}{*}{ Ano } & \multicolumn{2}{|c|}{ Pedestres } & \multicolumn{2}{|c|}{ Ciclistas } & \multicolumn{3}{|c|}{ Motociclistas } & \multicolumn{3}{|c|}{ Condutores } & \multicolumn{2}{|c|}{$\begin{array}{l}\text { Passa- } \\
\text { geiros }\end{array}$} & \multicolumn{2}{|c|}{$\begin{array}{c}\text { Não } \\
\text { especificado }\end{array}$} \\
\hline & & \multirow{2}{*}{$\begin{array}{c}T \\
(1)\end{array}$} & & \multirow{2}{*}{$\begin{array}{c}T \\
(1)\end{array}$} & & \multicolumn{2}{|c|}{1} & & \multicolumn{2}{|c|}{$T$} & \multirow{2}{*}{$\mathbf{N}$} & \multirow{2}{*}{$\begin{array}{c}T \\
\text { (1) }\end{array}$} & \multirow{2}{*}{$\mathrm{N}$} & \multirow{2}{*}{$\begin{array}{c}T \\
(1)\end{array}$} \\
\hline & & & & & & $(1)$ & & & $(1)$ & & & & & \\
\hline 2005 & 232 & 373 & 10 & 0,16 & 72 & & & 18 & & & 52 & 0,84 & 474 & 7,62 \\
\hline 2006 & & & & & & & & 15 & & & 22 & & 493 & 7,82 \\
\hline 2007 & 198 & & 1 & & & & & 15 & & & 43 & & 34 & 9,94 \\
\hline 2008 & 18 & & & & & & & & & & & & & 1,89 \\
\hline 2009 & 180 & & 15 & & & & 29 , & 11 & 7 & 3, & 51 & 78 & 723 & 11,07 \\
\hline 2010 & & & 8 & & & & & 22 & & & 84 & & & 11,90 \\
\hline 201 & & & & & & & & & & & & & & \\
\hline 2012 & 234 & 3,4 & 26 & 0,3 & 232 & & 39 , & 36 & 0,53 & 8,4 & 84 & 1,25 & 987 & 14,66 \\
\hline 2013 & 196 & & 21 & 0,3 & 248 & & 36,84 & 37 & 0,54 & & 74 & 1,09 & 939 & 13,82 \\
\hline 2014 & 194 & & 21 & & 325 & & & 46 & & & 110 & 1,61 & 989 & 14,44 \\
\hline 2015 & 162 & & 29 & 0,4 & 374 & & & 53 & & & 102 & 1,48 & 828 & 11,99 \\
\hline 2016 & 155 & 2,2 & 25 & 0,3 & 385 & & & 45 & 0,65 & 7,77 & 103 & 1,48 & 852 & 12,25 \\
\hline 2017 & 162 & & 14 & 0,2 & 311 & 4,4 & 32 & 41 & 0,59 & 6,77 & 66 & 0,94 & 726 & 10,37 \\
\hline Total & 2.542 & 2,94 & 231 & 0,27 & 2.545 & 2,95 & 37,75 & 381 & 0,44 & 7,58 & 903 & 1,05 & 10.115 & 11,71 \\
\hline
\end{tabular}

Legenda: T: Taxa

(1): Taxa de mortalidade por 100 mil habitantes

(2) : Taxa de mortalidade por 100 mil motocicletas

(3) : Taxa de mortalidade por 100 mil carros

Fonte: Sousa LHF, et al., 2021; dados extraídos do DATASUS (2018), IBGE (2018) e DENATRAN (2019).

Em relação ao sexo, nota-se predomínio da mortalidade no masculino, apresentando 13.858 mortes no período estudado, o que totaliza $82,90 \%$ das mortes por AT. Apesar do sexo masculino ser predominante em todos os grupos, o denominado "passageiros" foi aquele que apresentou maior taxa de mortalidade das mulheres (42,41\%) (Tabela 4).

Tabela 4 - Mortalidade total e taxa de mortalidade média por 100 mil habitantes, por grupo, segundo sexo.

\begin{tabular}{|c|c|c|c|c|c|}
\hline \multirow{2}{*}{ Grupo } & \multicolumn{2}{|c|}{ Masculino } & \multicolumn{2}{|c|}{ Feminino } & \multirow{2}{*}{$\begin{array}{l}\text { Em Branco ou } \\
\text { Ignorado (N) }\end{array}$} \\
\hline & $\mathbf{N}$ & Taxa & $\mathbf{N}$ & Taxa & \\
\hline Pedestres & 1.882 & 4,39 & 659 & 1,52 & 1 \\
\hline Ciclistas & 203 & 0,47 & 28 & 0,06 & - \\
\hline Motociclistas & 2.332 & 5,43 & 213 & 0,49 & - \\
\hline Condutores & 343 & 0,80 & 38 & 0,09 & - \\
\hline Não Especificado & 8.578 & 19,99 & 1.534 & 3,53 & 3 \\
\hline Passageiros & 520 & 1,21 & 383 & 0,88 & - \\
\hline Total & 13.858 & 32,30 & 2.855 & 6,56 & 4 \\
\hline
\end{tabular}

Legenda: N: Número de mortes no período de 2005 a 2017 - Dado numérico igual a zero

Fonte: Sousa LHF, et al., 2021; dados extraídos do DATASUS (2018) e IBGE (2018). 
A maioria dos mortos são adultos jovens, sendo a faixa de 20 a 29 anos de idade a que apresentou a maior quantidade de óbitos, e a faixa de 0 a 9 anos a menor mortalidade, tanto absoluta quanto por 100 mil habitantes. Ao analisar os grupos separadamente, nota-se que os idosos são os que mais vão à óbito no grupo dos pedestres e dos ciclistas. Entre os motociclistas, condutores, passageiros e não especificado, há predominância de adultos jovens (20 a 39 anos) (Tabela 5).

Tabela 5 - Mortalidade total e taxa mortalidade média por 100 mil habitantes segundo faixa etária.

\begin{tabular}{|c|c|c|c|c|c|c|c|c|c|c|c|c|c|c|}
\hline \multirow{2}{*}{$\begin{array}{l}\text { Idade } \\
\text { em anos }\end{array}$} & \multicolumn{2}{|c|}{ Pedestres } & \multicolumn{2}{|c|}{ Ciclistas } & \multicolumn{2}{|c|}{ Motociclistas } & \multicolumn{2}{|c|}{ Condutores } & \multicolumn{2}{|c|}{ Passageiros } & \multicolumn{2}{|c|}{$\begin{array}{c}\text { Não } \\
\text { Especificado }\end{array}$} & \multicolumn{2}{|c|}{ Total } \\
\hline & $\mathbf{N}$ & $T$ & $\mathbf{N}$ & $T$ & $\mathbf{N}$ & $T$ & $\mathbf{N}$ & $T$ & $\mathbf{N}$ & $T$ & $\mathbf{N}$ & $T$ & $\mathbf{N}$ & $T$ \\
\hline 0 a 9 & 219 & 1,16 & 5 & 0,03 & 0 & 0 & 0 & 0 & 59 & 0,31 & 211 & 1,11 & 494 & 2,61 \\
\hline $10-19$ & 222 & 1,25 & 14 & 0,08 & 330 & 1,85 & 22 & 0,12 & 177 & 0,99 & 1.093 & 6,14 & 1.858 & 10,43 \\
\hline $20-29$ & 377 & 2,34 & 44 & 0,27 & 889 & 5,53 & 90 & 0,56 & 245 & 1,52 & 3.063 & 19,05 & 4.708 & 29,28 \\
\hline 30-39 & 388 & 3,14 & 45 & 0,36 & 617 & 4,99 & 105 & 0,85 & 159 & 1,29 & 2.191 & 17,72 & 3.505 & 28,35 \\
\hline $40-49$ & 353 & 4,15 & 44 & 0,52 & 384 & 4,51 & 69 & 0,81 & 105 & 1,23 & 1.385 & 16,27 & 2.340 & 27,49 \\
\hline $50-59$ & 302 & 5,03 & 31 & 0,52 & 185 & 3,08 & 48 & 0,80 & 76 & 1,27 & 982 & 16,37 & 1.624 & 27,07 \\
\hline $60-69$ & 260 & 6,97 & 29 & 0,78 & 91 & 2,44 & 36 & 0,96 & 41 & 1,10 & 598 & 16,03 & 1.055 & 28,27 \\
\hline$\geq 70$ & 401 & 13,50 & 18 & 0,61 & 49 & 1,65 & 11 & 0,37 & 40 & 1,35 & 461 & 15,52 & 980 & 33,00 \\
\hline EB/I & 20 & - & 1 & - & 0 & - & 0 & - & 1 & - & 31 & - & 53 & - \\
\hline
\end{tabular}

Legenda: EB/I: Em branco/lgnorado; - Não calculado

Fonte: Sousa LHF, et al., 2021; dados extraídos do DATASUS (2018) e IBGE (2018).

Nota-se queda na mortalidade por AT no ano posterior ao surgimento da Lei Seca (BRASIL, 2008) e nos anos posteriores à alteração desta lei (2012 e 2016), registrando o decréscimo em 2009, 2013 e 2017, apresentando redução da taxa de mortalidade por 100 mil habitantes, em relação ao ano anterior, de 6,22\%; $6,07 \%$ e $16,18 \%$ respectivamente. (Figura 1).

Figura 1 - Taxa de mortalidade para 100 mil habitantes de 2005 a 2017 com alterações da Lei Seca.

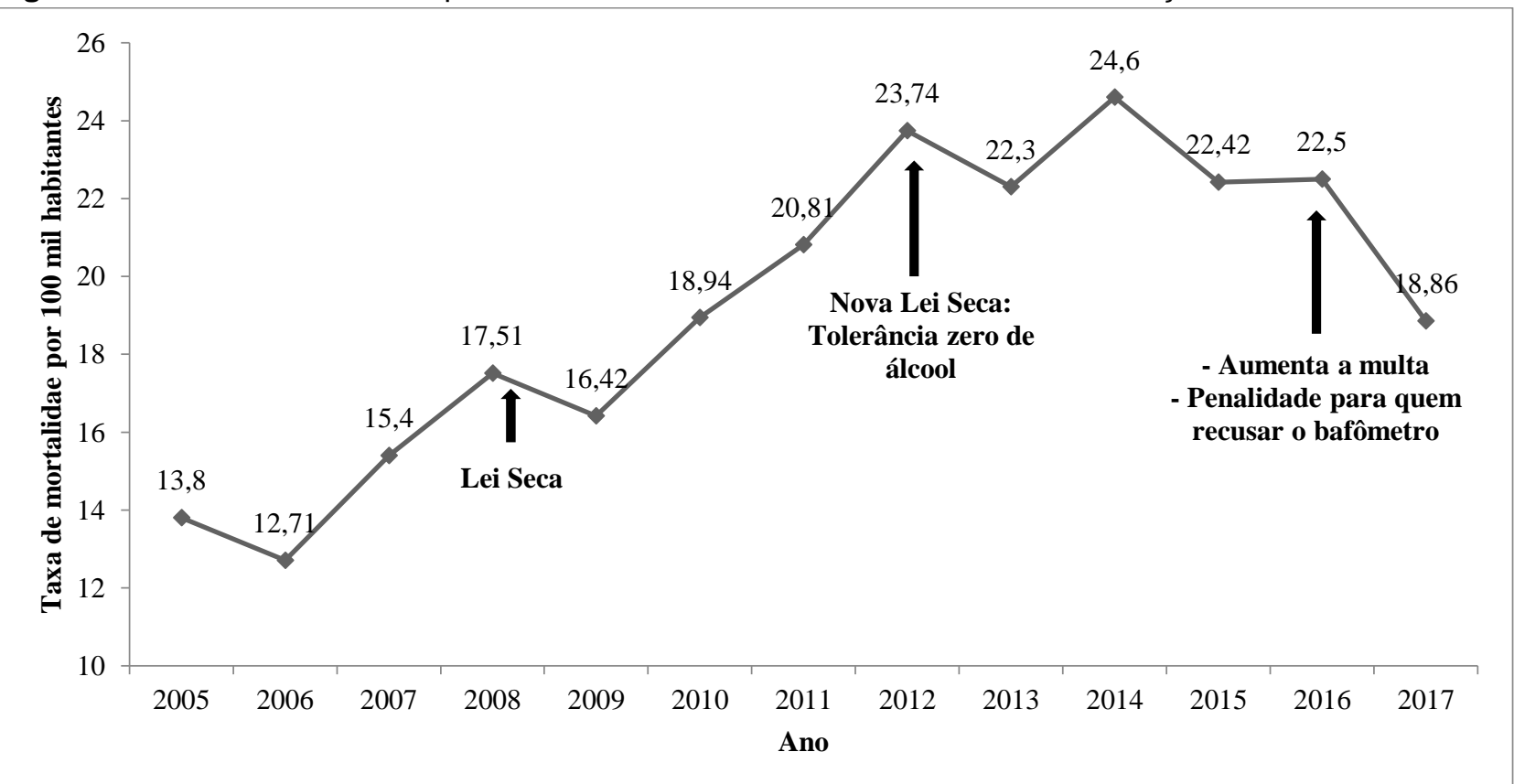

Fonte: Sousa LHF, et al., 2021; dados extraídos do DATASUS (2018) e IBGE (2018). 


\section{DISCUSSÃO}

A recomendação da OMS para que se declare que uma pessoa foi a óbito proveniente de um AT é de até trinta dias após a ocorrência de acidente de trânsito (MARÍN L e QUEIROZ MSA, 2020). Esta mesma recomendação é feita no Brasil pela Associação Brasileira de Normas Técnicas (ABNT) (MARÍN L e QUEIROZ MSA, 2020, BRASIL, 2018).

Ao se considerar as recomendações da ABNT e da OMS, é possível haver alterações nas estatísticas provenientes de morte no trânsito, devido à possibilidade de registrar o óbito por outro motivo. Além disso, uma parte das pessoas que sofreram AT e buscam os hospitais são identificados como acidentes em geral, gerando dificuldades maiores na obtenção de dados sobre a quantidade correta de pessoas que sofreram sequelas ou morte por AT (MARÍN L e QUEIROZ MSA, 2020).

Os AT podem ser causados por vários fatores ligados à saúde, tais como a presença de sintomas psiquiátricos menores, como ansiedade, e/ou eventos de vida desfavoráveis; desvio social leve, onde indivíduos com esse transtorno usariam a alta velocidade ao dirigir como um artifício de desafiar as leis (MARÍN L e QUEIROZ MSA, 2020; WEST R et al., 1993).

Outro fator importante no trânsito é a tomada de decisão, visto que o indivíduo está a todo momento sendo exigido a fazer escolhas, como mudar de faixa, alterar a velocidade, estacionar, sendo que essas decisões podem ser influenciadas por causas externas, como o ambiente, estresse ou por outras substâncias como 0 álcool, podendo levar a deliberações errôneas que podem precipitar AT (MARÍN L e QUEIROZ MSA, 2020).

Diversas outras razões podem ocasionar acidentes de trânsito, entre elas encontra-se o estado de preservação dos veículos, erro humano, qualidade das vias, sonolência e o uso de substâncias psicoativas (MARÍN L e QUEIROZ MSA, 2020; NUNES MN e NASCIMENTO LFC, 2012; ARAÚJO TA et al, 2015).

Entre as substâncias psicoativas encontra-se o álcool que, quando associado à falta de experiência, à busca por emoções, à satisfação em provar sensações de risco e à impulsividade, principalmente nos adolescentes e adultos jovens, pode ocasionar acidentes (ARAÚJO TA, et al., 2015; MALTA DC, et al., 2012).

Por outro lado, alguns mecanismos podem gerar maior segurança, e consequentemente a diminuição de sequelas e de morte por AT para os ocupantes do veículo, como o cinto de segurança e os air bags, apesar destes não trazerem segurança para terceiros, como os pedestres (MARÍN L e QUEIROZ MSA, 2020; EVANS L, 1996; WILHELM F e GARCIA RL, 2018).

Outros mecanismos, como mudanças na legislação, promoção de mudanças comportamentais, avanços na engenharia e segurança no trânsito, suspensão da habilitação dos infratores, certeza de que será punido ao ingerir bebida alcóolica e dirigir, aumento do controle das publicidades e de impostos sobre bebidas alcóolicas, entre outras, podem gerar reduções dos AT como um todo (PINSKY I e PAVARINO FILHO RV, 2007; MELLO JORGE MHP e KOIZUMI MS, 2009; MARÍN L e QUEIROZ MSA, 2020; BACCHIERI G e BARROS AJD, 2011).

Isso pode ser observado nesta pesquisa com a redução da mortalidade no ano posterior à Lei Seca e nos anos em que houve alguma alteração desta Lei, como em 2012, com a na nova Lei Seca em que a tolerância de álcool passou a ser zero além do aumento da multa para os infratores e o acréscimo da prova testemunhal ou de imagens como prova de comprovação do crime; em 2016 com o aumento novamente da multa e o acréscimo de penalidade para quem recusar o teste do bafômetro, apresentando decréscimo na taxa de mortalidade nos anos de 2009, 2013 e 2017 (BRASIL, 2012; BRASIL, 2016). Essa redução também foi observada quando entrou em vigor o Código de Trânsito Brasileiro em 1998, havendo redução na taxa de mortalidade nos anos de 1999 e 2000 (MELLO JORGE MHP e KOIZUMI MS, 2008).

Alguns estudos comprovam que houve diminuição nos AT após a promulgação da Lei Seca (KOIZUMI MS, et al., 2010; MELLO JORGE MHP e KOIZUMI MS, 2009; BACCHIERI G e BARROS AJD, 2011). Já outras pesquisas mostram que tal lei teve êxito em seu período inicial, havendo novo aumento dos acidentes nos meses posteriores; sugerindo que a sua eficácia foi por curto período de tempo e estando associado à baixa fiscalização (BACCHIERI G e BARROS AJD, 2011; MOURA EC, et al., 2009). 
Porém o que se observou no atual trabalho, foi que imediatamente às alterações da lei há queda na mortalidade, podendo isso estar associado à maior veiculação de notícias, juntamente com o aumento da fiscalização assim que ocorrem as alterações.

No ano de 1998 entrou em vigor o novo CTB, editado em 23 de setembro de 1997, estabelecendo punições mais severas, além de trazer uma parte voltada para a educação no trânsito, com o propósito de diminuir o número dos AT (BRASIL, 1997; BACCHIERI G e BARROS AJD, 2011). Contudo, em relação ao número de acidentes, não foi alcançado o objetivo esperado por tal código, pois o número de mortes em AT em 1998 eram 30.890 e passaram para 36.666 em 2008 , sendo que, quando comparado o percentual, houve aumento de $19 \%$ ao mesmo tempo em que a população brasileira aumentou 17\% (BACCHIERI G e BARROS AJD, 2011).

Mello Jorge MHP e Koizumi MS (2008), ao analisarem o panorama da mortalidade no trânsito de 1995 a 2005 encontraram uma taxa de mortalidade no Brasil de 19,40 mortes por 100 mil habitantes no ano de 2005, valor superior ao encontrado no estado do Maranhão nesse mesmo ano, que foi de 13,80 , porém bem próximo ao encontrado no período de 2005 a 2017, que foi de 19,35 mortes por 100 mil habitantes.

Os pedestres são a terceira principal vítima de AT, porém são os que mais vão a óbito. Em estudo relacionado à cidade de Maringá-PR, em relação ao risco de internação hospitalar, foi informado que os pedestres têm risco 119\% maior que ocupantes de automóveis, sendo a maior parte composta por idosos (BACCHIERI G e BARROS AJD, 2011; SOARES DFP e BARROS MBA, 2006).

O mesmo foi observado nesta pesquisa em que, no grupo de óbitos de pedestres, os idosos foram a maioria tanto em números absolutos (661) quanto em taxa de mortalidade por 100 mil habitantes. Além disso, observou-se que nesse grupo teve queda de $38,07 \%$ de 2005 a 2017, achado que também foi encontrado por Mello Jorge MHP e Koizumi MS (2008) ao analisar o período de 1995 a 2005.

Quando desconsiderado o grupo denominado "Não Especificados", o grupo dos pedestres foi o segundo com maior mortalidade, perdendo apenas para os motociclistas, porém ambos com quantidades de óbitos bem próxima (2.542 e 2.545 respectivamente), ao contrário do que foi encontrado por Mello Jorge MHP e Koizumi MS (2008) em que os pedestres eram os grupos que apresentavam maior mortalidade (35\%) seguido dos motociclistas (25\%).

Isso pode ser explicado pela grande ascensão da mortalidade dos motociclistas, que foi o grupo que apresentou o maior aumento no período estudado, chegando a cerca de $282 \%$, ascensão corroborada por outros autores que encontraram alta de $540 \%$ no período de 1995 a 2005 e de $700 \%$ no período de 1998 a 2008, além de demostrarem o aumento da mortalidade desse grupo (MELLO JORGE MHP e KOIZUMI MS, 2008; MELLO JORGE MHP e KOIZUMI MS, 2009; BACCHIERI G e BARROS AJD, 2011).

A taxa de mortalidade por 100 mil veículos pode ter tido uma redução devido ao grande aumento na frota, com isso mais veículos ficam parados e são usados apenas em alguns momentos (BARROS AJD, et al., 2003), indo de encontro aos dados obtidos neste trabalho, em que a redução da mortalidade pela quantidade de veículos foi expressiva, pois, no período estudado, a quantidade de veículos teve um aumento de $363,81 \%$ enquanto a população aumentou apenas $11,82 \%$. O aumento da frota apontado neste estudo foi bem superior ao encontrado por Mello Jorge MHP e Koizumi MS (2009) que, de 1995 a 2008, observaram um aumento de $58 \%$ na frota.

Quando se leva em consideração a faixa etária, os idosos são aqueles que têm maior taxa de mortalidade (33 óbitos por 100 mil habitantes), achado também encontrado por Mello Jorge MHP e Koizumi MS (2008).

A mortalidade maior no sexo masculino apontada por outros estudos, com uma razão de 4,5 homens para cada mulher, é confirmada nesta pesquisa, onde ocorre taxa de uma mulher para cada 4,8 homens (BARROS AJD, 2003; MELLO JORGE MHP e KOIZUMI MS, 2008; MELLO JORGE MHP e KOIZUMI MS, 2009; BACCHIERI G e BARROS AJD, 2011). Isso ocorre devido aos acidentes envolvendo mulheres serem menos graves e apresentarem uma menor letalidade (ANDRADE SM e MELLO JORGE MHP, 2000). 


\section{CONCLUSÃO}

A mortalidade no trânsito, apesar do aumento significativo durante o período estudado, apresenta picos de redução nos anos da implantação da Lei Seca e nos anos em que houveram alterações com punições mais severas. No estado do Maranhão, observou-se que o sexo masculino continua sendo o mais atingido, com destaque para o grupo de adultos jovens. O grande aumento da mortalidade encontrado no grupo de motociclistas enfatiza a necessidade de ações de educação e prevenção de acidentes de trânsito, direcionadas a este grupo, sendo necessário pensar em políticas públicas que visem diminuir a mortalidade desse grupo. Constatou-se também que em 2014 apresentou a maior mortalidade por AT do período de estudo. Ainda foi possível constatar o grande aumento da frota de veículos, chamando atenção para políticas públicas que visem melhorar o transporte público. Informar com mais ênfase a população sobre as regras de trânsito e o efeito de algumas substâncias que podem alterar o nível de consciência, como o consumo de álcool, pode diminuir os índices de mortalidade por AT, bem como o aumento da fiscalização de trânsito.

\section{REFERÊNCIAS}

1. ABREU AMM, et al. Uso de álcool em vítimas de acidentes de trânsito: estudo do nível de alcoolemia. Revista LatinoAmericana de Enfermagem, 2010; 18: 513-520.

2. ANDRADE SM, JORGE MHPM. Características das vítimas por acidentes de transporte terrestre em município da Região Sul do Brasil. Revista de Saúde Pública, 2000; 34(2): 149-156.

3. ARAÚJO TA, et al. Acidentes de trânsito e sua relação com o consumo de álcool: revisão integrativa. Revista de Enfermagem da UFPE on line. 2015; 5: 8437-8443.

4. ASSOCIAÇÃO BRASILEIRA DE NORMAS TÉCNICAS. ABNT NBR 10697: Pesquisa de acidentes de trânsito Terminologia. Rio de Janeiro: ABNT; 2018.

5. BACCHIERI G, BARROS AJD. Acidentes de trânsito no Brasil de 1998 a 2010: muitas mudanças e poucos resultados. Revista de Saúde Pública, 2011; 45(5): 949-963.

6. BARROS, AJD, et al. Acidentes de trânsito com vítimas: sub-registro, caracterização e letalidade. Cadernos de Saúde Pública, 2003; 19(4): 979-986.

7. BRASIL. Lei $n^{\circ} 11.705$, de 19 de junho de 2008. Altera a Lei no 9.503, de 23 de setembro de 1997, que 'institui o Código de Trânsito Brasileiro', e a Lei no 9.294, de 15 de julho de 1996, que dispõe sobre as restrições ao uso e à propaganda de produtos fumígeros, bebidas alcoólicas, medicamentos, terapias e defensivos agrícolas, nos termos do $\S 40$ do art. 220 da Constituição Federal, para inibir o consumo de bebida alcoólica por condutor de veículo automotor, e dá outras providências. Disponível em < http://www.planalto.gov.br/ccivil_03/_ato20072010/2008/lei/l11705.htm>. Acesso em: 26 out 2020.

8. BRASIL. Lei no 9503, de 23 de setembro de 1997. Institui o Código Brasileiro de Trânsito. Disponível em < http://www.planalto.gov.br/ccivil_03/leis/L9503Compilado.htm\#: :text=LEl\%20N\%C2\%BA\%209.503\%2C\%20DE\%2 023\%20DE\%20SETEMBRO\%20DE\%201997\&text=Institui\%200\%20C\%C3\%B3digo\%20de\%20Tr\%C3\%A2nsito\%2 0Brasileiro.\&text=Art.\%201\%C2\%BA\%200\%20tr\%C3\%A2nsito\%20de,rege\%2Dse\%20por\%20este\%20C\%C3\%B3 digo.> Acesso em: 26 out 2020.

9. BRASIL. Lei nำ12. 760, de 20 de dezembro de 2012. Altera a Lei nำ. 503, de 23 de setembro de 1997, que institui o Código de Trânsito Brasileiro. Disponível em

< http://www.planalto.gov.br/ccivil_03/_ato20112014/2012/lei//12760.htm> Acesso em:26 out 2020.

10. BRASIL. Lei nำ13. 281, de 4 de maio de 2016. Altera a Lei nำ. 503, de 23 de setembro de 1997 (Código de Trânsito Brasileiro), e a Lei no 13.146, de 6 de julho de 2015. Disponível em < http://www.planalto.gov.br/ccivil_03/_ato20152018/2016/lei/l13281.htm\#: :text=Medida\%20administrativa\%20\%2D\%20remo\%C3\%A7\%C3\%A3o\%20do\%20ve\% C3\%ADculo.\&text=1\%20\%2D\%20infra\%C3\%A7\%C3\%A30\%20de\%20natureza\%20grav\%C3\%ADssima,quarenta\% 20e\%20sete\%20centavos)\%3B\&text=IV\%20\%2D\%20infra\%C3\%A7\%C3\%A30\%20de\%20natureza\%20leve,\%C2\% A7\%201\%C2\%BA\%20(Revogado).> Acesso em: em 20 out 2020.

11. CID-10- Classificação Internacional de Doenças e Problemas Relacionados à Saúde/Classificação Internacional de Doenças (CID-10), disponível em <www.medicinanet.com.br> Acesso em 20 out 2020.

12. DAMACENA GN, et al. Consumo abusivo de álcool e envolvimento em acidentes de trânsito na população brasileira, 2013. Ciência e saúde coletiva, 2016; 21(12): 3777-3786.

13. DENATRAN [Internet]. Brasília: Ministério da Infraestrutura; c2019. Departamento Nacional de Trânsito. Disponível em: https://www.denatran.gov.br/component/content/article/115-portal-denatran/8552-estat\%C3\%ADsticas-frota-deve\%C3\%ADculos-denatran.html. Acesso em: 10 jan 2019.

14. DEPARTAMENTO DE INFORMÁTICA DO SUS - DATASUS. Brasília: Ministério da saúde; c2018. Disponível em: http://datasus.saude.gov.br/ Acesso em: 15 dez 2018.

15. EVANS L. The dominant role of driver behavior in traffic safety. American Journal of Public Health, 1996; 86(6):784786.

16. INSTITUTO BRASILEIRO DE GEOGRAFIA E ESTATÍSTICA - IBGE. Rio de Janeiro: IBGE; c2018. Disponível em: https://www.ibge.gov.br/estatisticas/sociais/populacao/9109-projecao-dapopulacao.html?edicao=9116\&t=resultados. Acesso em: 15 dez 2019. 
17. INSTITUTO DE PESQUISA ECONÔMICA APLICADA (IPEA). Estimativa dos Custos dos Acidentes de Trânsito no Brasil com Base na Atualização Simplificada das Pesquisas Anteriores do Ipea [Internet]. Brasília: IPEA; Disponível em: http://repositorio.ipea.gov.br/bitstream/11058/7456/1/RP_Estimativa_2015.pdf. Acesso em: 15 dez 2019.

18. INSTITUTO DE PESQUISA ECONÔMICA APLICADA (IPEA). Impactos sociais e econômicos dos acidentes de trânsito nas rodovias brasileiras. Brasília: IPEA/DENATRAN/ANTP; 2006. Disponível em: http://infraestrutura.gov.br/images/Educacao/Publicacoes/custos_acidentes_transito.pdf. Acesso em: 15 dez 2018.

19. KOIZUMI MS, et al. Alcoolemia e mortalidade por acidentes de trânsito no Município de São Paulo, $2007 / 2008$. Revista ABRAMET, 2010; 28(1): 25-34.

20. MALTA DC, et al. Atendimentos por acidentes de transporte em serviços públicos de emergência em 23 capitais e no Distrito Federal - Brasil, 2009. Epidemiologia e Serviços de Saúde, 2012; 21(1): 31-42.

21. MARIN L, QUEIROZ MS. A atualidade dos acidentes de trânsito na era da velocidade: uma visão geral. Cadernos de Saúde Pública, 2000; 16(1): 7-21.

22. MELLO JORGE MHP, KOIZUMI MS. Acidentes de trânsito causando vítimas: possível reflexo da lei seca nas internações hospitalares. Revista ABRAMET;2009; 27(2):16-25.

23. MELLO JORGE MHP, KOIZUMI MS. Acidentes de trânsito no Brasil: um atlas de sua distribuição. Revista ABRAMET; 2008; 26(1): 52-58.

24. MOURA EC, et al. Direção de veículos motorizados após consumo abusivo de bebidas alcoólicas, Brasil, 2006 a 2009. Revista de Saúde Pública, 2009; 43(5): 891-894.

25. NUNES MN, NASCIMENTO LFC. Análise espacial de óbitos por acidentes de trânsito, antes e após a Lei Seca, nas microrregiões do estado de São Paulo. Revista da Associação Médica Brasileira, 2012; 58(6): 685-690.

26. PINSKY I, PAVARINO FILHO RV. A apologia do consumo de bebidas alcoólicas e da velocidade no trânsito no Brasil: considerações sobre a propaganda de dois problemas de saúde pública. Revista de Psiquiatria do Rio Grande do Sul, 2007; 29(1): 110-118.

27. SADOCK BJ, et al. Compêndio de psiquiatria: ciência do comportamento e psiquiatria clínica. Porto Alegre: Artmed; 2017. 1584p.

28. SOARES DFPP, BARROS MBA. Fatores associados ao risco de internação por acidentes de trânsito no Município de Maringá-PR. Revista Brasileira de Epidemiologia, 2066; 9(2): 193-205.

29. WEST R, et al. Mild social deviance, Type-A behaviour pattern and decision-making style as predictors of self-reported driving style and traffic accident risk. British Journal of Health Psychology, 1993; 84(2): 207-219.

30. WILHELM F, GARCIA RL. Equipamentos de segurança veicular: uma análise da legislação brasileira. Revista Eletrônica Científica da UERGS, 2018; 4,(2): 283-298. 